\title{
Experience in Project-Oriented Professional Activities in The Digital Educational Environment of a School
}

\author{
Elena Egorovna Dmitrieva ${ }^{1 *}$, Grigory Nikolaevich Kovalev $^{2}$, Vladimir Vladimirovich \\ Churin $^{3}$, and Mark Aleksandrovich Iskumenko ${ }^{4}$ \\ ${ }^{1}$ Moscow University of the Ministry of Internal Affairs of Russia named after V.YA. Kikot, Ryazan \\ branch, Social-Humanity Department, Ryazan, Russia \\ ${ }^{2}$ Moscow City University, Pedagogy Department, Moscow, Russia \\ ${ }^{3}$ Moscow Automobile and Road Construction State Technical University (MADI), Sociology and \\ Management Department, Moscow, Russia \\ ${ }^{4}$ College of Entrepreneurship No. 11, Moscow, Russia
}

\begin{abstract}
Today, education is being modified to meet the requirements of the digital environment. The educational function of the school is already being implemented using digital means. Therefore, it is possible to predict attempts to implement the upbringing function of the school in a digital environment. The purpose of the present research is to test professionallyoriented projects as a measure of pedagogical support for students' professional choice in the context of the school's digital educational environment. The methods to study professional interests included the use of the survey form proposed by G.V. Rezapkina and the questionnaire of N.S. Pryazhnikov. The method of creating professionally-oriented projects has become an instrumental method of pedagogical support for professional choice. The results of the study included examples of tasks that could be used to organize professionally-oriented projects in the context of the school's digital educational environment. The experience of implementing these projects shows that the development of technologies for pedagogical support of professional choice employing the digital educational environment of the school is quite promising.
\end{abstract}

\section{Introduction}

The status and prospects of digitalization of education are one of the most discussed problems of today's pedagogy. Since there is an experience in complete transferring of the educational process to a digital environment, the modification of the educational and career guidance functions of a teacher to the framework of the digital environment is just a matter of time.

Every year, technologies for creating a digital educational environment (DEE) become more diverse. Special attention is paid to massive open online courses (MOOCs), i.e. "a structured, methodically based, the purposeful sequence of educational and methodological

\footnotetext{
*Corresponding author: dmitrieva_ee91@mail.ru
} 
control and measurement materials and other means for the implementation of educational activities in the e-learning format" [1].

However, MOOCs that have proven themselves in the higher education system [2, 3] have not yet been transferred to the general education system, although attempts have been made to create a theoretical model of MOOC for primary general education [4]. This is due to several limitations of distance learning, which are noticeable for students, but insurmountable for schoolchildren due to age characteristics. It is also noted that "the degree, to which the teacher can focus the attention (interest) of students in a particular area" significantly affects the motivation of students: someone leaves the topic unexplored, and someone, having delved into the solution of a particular task, loses interest in others" [3] that is unacceptable in the framework of general education, which assumes a standardized basic level of competencies. At the same time, the need to transfer learning to a digital environment challenges the educational process participants to focus on the development of selfregulation, which is considered as the basis of all skills for the 21 st-century students $[5,6]$.

Besides, according to Ya. Sherman: "...students now need first of all skills for a successful life and career growth in the digital environment, such as creativity, critical thinking, ability to work in a team and maintain communication" [7], while the existing MOOCs are not able to solve the set tasks [8].

The analysis of scientific works on the topic of digitalization of general education has shown that teachers are busy searching for solutions to the problem of adaptation to changing conditions of the DEE, rather than theoretical study and scientific forecast. The environment with its functional opportunities, design, and technical characteristics is a constant, while the ways and technologies of using DEE, employed by the teacher in the educational process, vary based on the teacher's goals and competencies $[9,10]$.

The purpose of the present study was to test professionally-oriented projects as one of the measures of pedagogical support for the professional choice of schoolchildren in the context of the school's DEE. To achieve this goal, professionally-oriented projects were developed, whose implementation was possible only with the use of DEE funds, as well as the effectiveness and resource cost of the measures taken for pedagogical support for the further development of this area of educational activity in the context of the DEE were evaluated.

\section{Methods}

The experiment was conducted based on the $52^{\text {nd }}$ Lyceum of Ryazan. The DEE of the Lyceum is organized based on the "BARS. Education - E-school"1 module, which allows teachers to keep an electronic journal, lesson-based planning, conduct electronic testing, as well as communicate with parents and students in the educational social network. At that, students and their parents get access to all grades and homework, and the information about any changes in the schedule. BARS is the integrated framework for digitization activities in the field of school education, whose implementation in the system improves quality control of the educational process and ensures its openness.

To obtain empirical data on the essence of the school's DEE, a questionnaire was developed containing questions about the material and program content of the DEE, the regularity, frequency, and specifics of using DEE means to achieve educational goals.

To diagnose the presence/absence of professional choice, as well as to determine the professional orientation, the "Questionnaire of professional self-determination" by G.V. Rezapkina was used [11].

To determine the readiness to choose a profession, the authors used the questionnaire of the personal professional perspective of N.S. Pryazhnikov [12]. 


\section{Results}

The survey conducted among students and teachers has shown that the most demanded features were the electronic journal and electronic diary (87\% of teachers and $91.5 \%$ of students used them daily). Communication and information take place in specialized groups in social networks and messengers $(52.25 \%$ of teachers and $55 \%$ of students communicate daily on educational issues). Therefore, it is impossible to exclude these communication platforms from the school's DEE.

Most teachers $(65 \%)$ have a list of electronic textbooks and educational resources that they use and recommend to students. This also needs to be kept in mind when talking about the school's DEE.

Career guidance is the teacher's task, and therefore, ideally, the school should provide conditions for professional self-determination. For objective reasons, the school does not always have experimental sites that would allow students to try their hand at professional activities. In turn, the DEE makes it possible to create and help to implement professionallyoriented projects.

Testing of professionally-oriented projects as one of the measures of pedagogical support in the context of DEE was carried out involving students of the 8th grade. This category was chosen for several reasons. First, as noted by L.I. Bozhovich, a qualitative change in motives of the students begins by the age of 15 , and those related to life plans and self-determination come out in the first place [13]. Secondly, based on the features of the educational process in the concerned school, the division into specialized classes takes place after the 9th grade. Thus, conducting experimental work involving students of the 8th grade is the only way to coordinate the sensitive period and today's realities of the educational process.

As a result of the conducted questionary survey of 28 students, six of them wanted to be doctors (two of them dentists), four - IT specialists (two animators), two - lawyers, one economist, one - speech pathologist, one - interpreter, one - architect, one - travel agent, one - military, one - producer, one - mathematician, and eight people were yet undecided about the choice of profession.

For each student, who chose the desired profession, a task was drawn up in the form of a project, whose implementation was associated with future professional activities.

The peculiarity of the projects was that for their creation and implementation, students had to use all the means of the DEE, namely, material (personal computers, pads, etc.), software and networks (electronic libraries, open banks of educational materials, etc.), communication and instrumental means (accounts and groups in social networks and messengers, etc.). Completed projects were available to all participants of the DEE of this school on the website and/or in social networks.

The framework of the present article provides an opportunity to describe in detail the essence and progress of three professionally-oriented projects.

Students who chose the profession of dentists were asked to create a presentation and/or video for younger pupils about what a tooth is, why baby teeth fall out, how to properly brush teeth, and what products are useful for teeth.

At the first stage, the consultant discussed the dentist's functions with the students. It turned out that students had some ideas about the technical function of the dentist, such as a dental checkup, tooth canal filling, and tooth extraction. When asked about the educational function of the dentist, students recalled the recommendation to brush their teeth twice a day. In the course of the joint discussion, the consultant tried to arrange the discussion so that students realized the need for preventive health communication with the dentist. Besides, it was proposed to survey students of the 4th grades about whether they know how many times to brush their teeth, what foods were useful for teeth, and why baby teeth fell out. This survey was recommended to make eighth-graders aware of the project's goal and increase their 
motivation to complete it. The consultant repeatedly emphasized the social significance of their work.

After demonstrating the project, the consultant discussed with the eighth-graders their immersion in the professional sphere. Students noted that the searching for special information and its layout did not differ from the performance of a school task. The feeling of a certain professional identity appeared after the demonstration of the project, when younger students began to ask questions, wanting to get answers from real professionals.

Another project was a combined task for a travel agent and an economist. The student who has chosen the profession of travel agent was asked to design two tours: to a European country and Russian cities. The cost of tours, as well as the customer's cultural preferences, and transportation means were specified.

After the demonstration of the project, the student noted that it was especially interesting to make a promotional booklet and talk about the proposed tour.

The student who chose the profession of an economist was asked to make comparative tables to demonstrate visually the tour price in various equivalents, namely, in payment for utility services, travel costs, and food.

At first, the consultant did not demonstrate interest, because of the lack of personal significance of the project. Then the student's parents have joined the project. Parents' task was to tell about the daily expenses for travel, food, and utilities. The student recorded data in a special Excel Table. During the month, the student together with his parents filled in the Table and then compared the expenses for food, travel, and utilities with the agreed cost of the tours.

The conscious professional-oriented activity has begun after the tour project compiled by a classmate was demonstrated. After evaluating the content and presentation of the project, the student independently rethought the goal of his project: to convince a fictional client not to buy a tour.

A discussion was organized among students of the 8th grade. This topic aroused interest, while the student himself, who was performing a project on economics, admitted that due to the task, he began to look differently at the price of things.

Experience in performing professionally-oriented projects contributes not only to immersion in the professional sphere, but also to the development of meta-subject skills, and activation of self-analysis. The execution of professionally-oriented projects allows moving away from mass education at school to the development of students' potential, which is a necessary course of educational policy in contemporary schools [14].

The work performed has shown that organizing the project-oriented professional activities requires the joint work of a team of teachers specializing in specific subjects, as well as a class teacher, and a school psychologist. The authors do not consider this type of activity as the only true one for providing pedagogical support for students' professional choice, and the tasks developed are not claimed as unchangeable samples of cases for professionally-oriented projects. Fully sharing the opinion that any innovative activity of a teacher becomes a useless ritual if focused just on mechanical external repetition and remembering [10; p. 26], the authors just describe the personal experience of solving the problem of providing pedagogical support for making a professional choice using the capabilities of the DEE.

\section{Conclusion}

The educational environment of the school is today the integration of physical and digital educational environments. The DEE not only duplicates some elements of the educational environment but also expands the educational opportunities of the school in general. In 
particular, the DEE provides an opportunity to organize professionally-oriented activities for each student, taking into account their chosen profession.

The study of the features of the DEE and its impact on participants is necessary to form and develop DEE that would provide a comfortable interaction of the educational process participants, which would contribute to the achievement of learning results and upgrading tasks. The study of the DEE is also necessary to comprehend the constraints of this environment that will allow distributing correctly the activity of participants in the educational process in the physical and digital educational environments.

\section{References}

1. T. Bystrova, V. Larionova, E. Sinitsyn, A. Tolmachev, Educational Studies 4, 139-166 (2018)

2. W. Al-Rahmi, A. Aldraiweesh, N. Yahaya, Y.B. Kamin, A.M. Zeki, Data in Brief 22,118-125 (2019)

3. W.D. Maxwell, P.H. Fabel, V. Diaz, J.C. Walkow, N.C. Kwiek, S. Kanchanaraksa, M. Wamsley, A. Chen, P.B. Bookstaver, Currents in Pharmacy Teaching and Learning 10(6), 736-743 (2018)

4. V.V. Afanasyev, I.V. Afanasyeva, S.M. Kunitsyna, Problems of modern education 1, 150-158 (2019)

5. E. Delen, J. Liew, V. Willson, Computers \& Education 78, 312-320 (2014)

6. R.S. Jansen, A. van Leeuwen, J. Janssen, R. Conijn, L. Kester, Computers \& Education 146, (2020)

7. Y. Sherman, Issues of Education 4, (2018)

8. D. Robertshaw, I. Babicova, Nurse Education in Practice 42, (2020)

9. I. Malgarov, Scientific electronic journal Meridian 4(15), 141-143 (2018)

10. V.A. Bogusha, P.A. Lisa, V.I. Slizha, A.B. Belsky, T.M. Shaverdo, O.V. Afanasenko, Digital Transformation of Education (Establishment "Main Information and Analytical Center of the Ministry of Education of the Republic of Belarus", Minsk, 2018)

11. G. Rezapkina, Schoolchildren's willingness to choose a profession, Interfax Available at:

https://academia.interfax.ru/attachment/19/Rozapkina\%20Psychological\%20readiness $\% 20 \mathrm{k} \% 20$ choice of a profession20.pdf

12. N. S. Pryazhnikov, Professional self-determination: theory and practice (Academiya, Moscow, 2007)

13. L.I. Bozhovich, Personality and its formation in childhood (Piter, St. Petersburg, 2008) Available at: http://elib.gnpbu.ru/text/bozhovich_lichnost-i-ee-formirovanie_2008/

14. O.V. Rogach, E.V. Frolova \& T.M. Ryabova, European Journal of Contemporary Education 7, 804-812 (2018)

15. A. P. Usoltsev, E. P. Antipova, Education and science 21(5), 9-41 (2019

16. M. Janelli, Educational Studies 4, 81-98 (2018) 